\title{
Vectorial wall shear stress calculations in vessel structures using 4D PC-MRI
}

\author{
Wouter $V$ Potters ${ }^{1,2^{*}}$, Pim van Ooij ${ }^{1,2}$, Ed vanBavel $^{2}$, Aart Nederveen ${ }^{1}$ \\ From 15th Annual SCMR Scientific Sessions \\ Orlando, FL, USA. 2-5 February 2012
}

\section{Summary}

We propose a fully automated method for calculating vectorial wall shear stress (WSS) in-vivo based on 4D PC-MRI data.

\section{Background}

Wall shear stress (WSS) is the tangential force of flowing blood on the vessel wall. WSS directly influences remodeling of the vessel wall.

\section{Methods}

Velocity data were corrected for aliasing and phase offsets and subsequently filtered using a median filter. Inward unit normal vectors were determined on the wall, after which a coordinate transformation was performed for each point at the wall such that the normal vector coincided with the $\mathrm{z}$-axis of the transformed coordinate system. Velocities at fixed points along the normal were calculated using natural 3D interpolation in the original data. Any perpendicular velocity components were removed as only tangential velocity components contribute to the viscous forces at the wall. Smoothing splines were then fitted to the $x$ - and $y$ velocity components along the inward unit normals. The $\mathrm{x}$ - and $\mathrm{y}$-derivatives at the vessel wall were derived analytically and multiplied with the viscosity, which resulted in the WSS. Finally, all WSS vectors were transformed back to the original coordinate system.

This method was validated using a synthetic dataset of a rigid straight tube (diameter $6 \mathrm{~mm}$ ) with parabolic flow, in which the theoretical WSS could be derived analytically (Poiseuille). Effects of resolution, segmentation errors and noise were assessed using this phantom data. Secondly the algorithm was tested in in-vivo PCMRI data. In vivo PC-MRI of the common carotid

${ }^{1}$ Radiology, Academic Medical Centre, Amsterdam, Netherlands Full list of author information is available at the end of the article artery was performed on a 3T MRI system (Philips Healthcare, Best, The Netherlands) using a dedicated 8 channel carotid coil, 5 heart phases, FOV $80 \times 80 \times 12$ $\mathrm{mm}$, isotropic voxel size $0.4 \mathrm{~mm}$ (non-interpolated), sense factor 2, Venc of 30 (ap), $30(\mathrm{rl})$ and $70(\mathrm{fh}) \mathrm{cm} / \mathrm{s}$, scantime 10 minutes.

\section{Results}

The phantom study reveals that increasing the resolution will result in improved approximations of the theoretical WSS (figure 1a). Additionally the standard deviation (SD) of WSS declines with increasing resolution (figure 1a). Secondly, the effect of false segmentations (change in diameter) on the calculated WSS was substantial (figure 1b). Addition of Gaussian white noise had a limited impact on the SD in WSS calculations (5\% increase for noise with $4 \mathrm{~cm} / \mathrm{s}$ variance, $15 \%$ increase for noise with $16 \mathrm{~cm} / \mathrm{s}$ variance).

The in-vivo WSS shows good visual resemblance with the measured flow profile. The calculated WSS values are within the physiological range (figure 2).

\section{Conclusions}

This work presents a new method to determine WSS invivo independent of assumptions on the flow profile. Results suggest that a resolution of at least $0.6 \mathrm{~mm}$ should be used for a $6 \mathrm{~mm}$ diameter vessel to calculate the WSS within $10 \%$ of theoretical values. High-resolution images are needed to avoid segmentation errors. Further validation of the algorithm in-vivo is planned.

\section{Funding}

None.

\section{Author details}

${ }^{1}$ Radiology, Academic Medical Centre, Amsterdam, Netherlands. ${ }^{2}$ Biomedical Engineering and Physics, Academic Medical Centre, Amsterdam, Netherlands. 


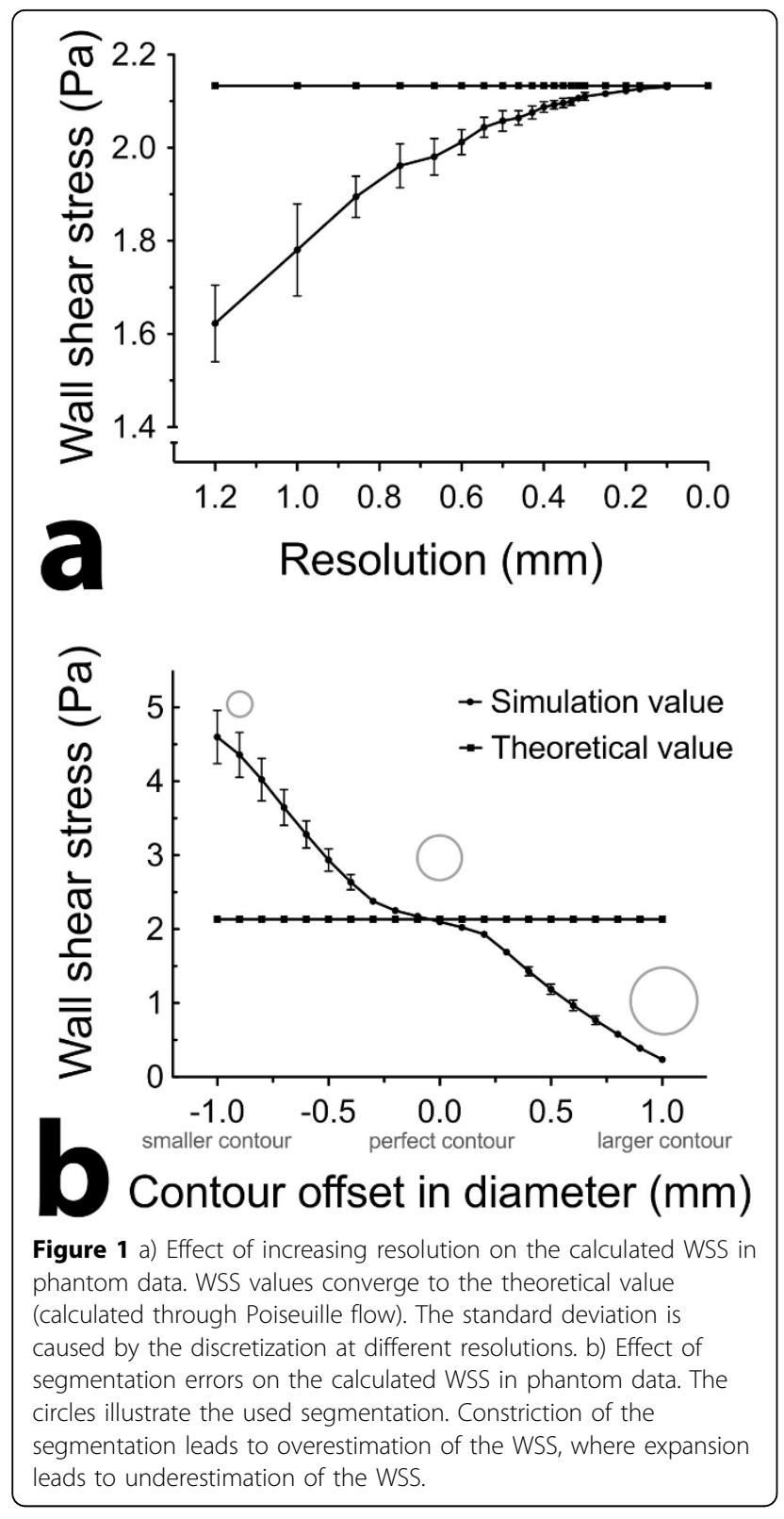

Published: 1 February 2012

doi:10.1186/1532-429X-14-S1-W5

Cite this article as: Potters et al:: Vectorial wall shear stress calculations in vessel structures using 4D PC-MRI. Journal of Cardiovascular Magnetic Resonance 2012 14(Suppl 1):W5.

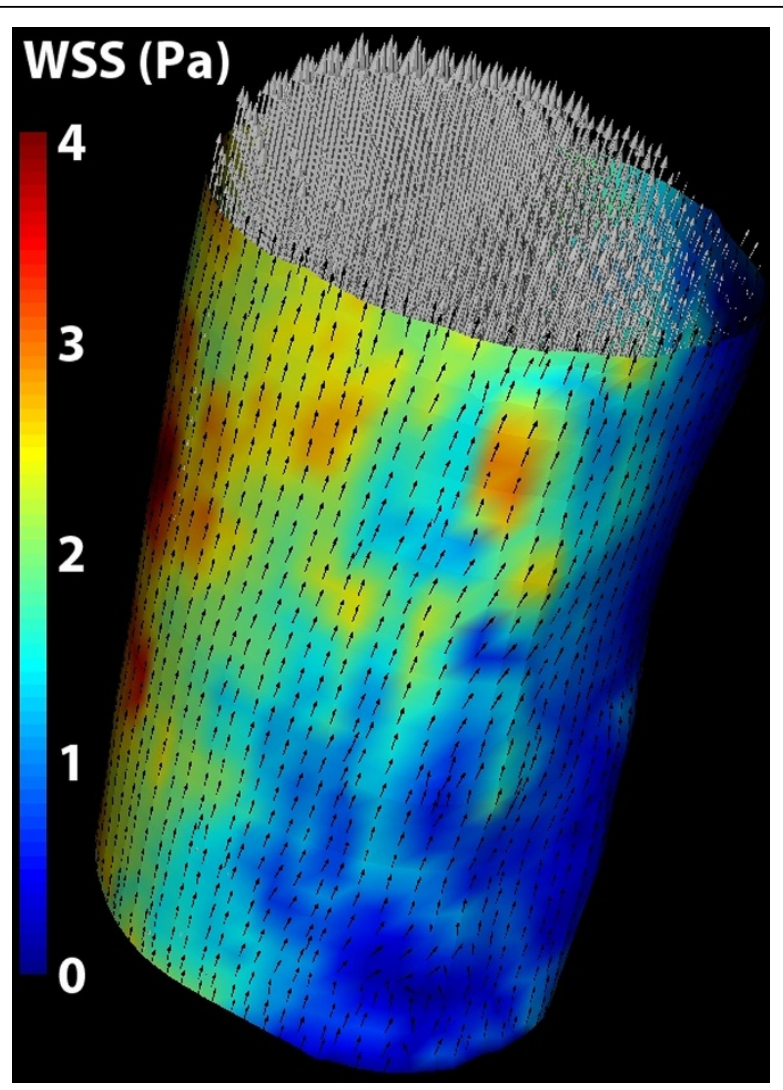

Figure 2 Wall shear stress calculated in an in-vivo measurement of the common carotid artery. Velocity vectors are shown as white quivers, normalized WSS vectors are shown as black arrows on the wall. Colors visualize the WSS magnitude.
Submit your next manuscript to BioMed Central and take full advantage of:

- Convenient online submission

- Thorough peer review

- No space constraints or color figure charges

- Immediate publication on acceptance

- Inclusion in PubMed, CAS, Scopus and Google Scholar

- Research which is freely available for redistribution
Biomed Central 